\title{
Paper yabber: The messenger and the message
}

\author{
Rob Foster
}

\section{Introduction}

One of the tasks often given to Aboriginal people on the Australian frontier was that of messenger, and the messages they carried, usually letters, came to be known by the Pidgin English phrase 'paper yabber' or, less commonly, 'paper talk'. The first part of the paper will examine characteristic features of the Aboriginal role as messenger, or 'mailman'. The second part is a study of the Australian folklore that sprang up around the practice, in particular the seemingly ubiquitous story of paper yabber and the 'tobacco thief'. In tracing the history of this story, and its variants, one not only gets an insight into the function of popular stereotypes, but also the mechanisms by which they are transmitted.

\section{The messengers}

The utilisation of Aborigines as message carriers for Europeans developed very early on the Australian frontier and was an extension of the Aboriginal role as guide. Daniel Brock records an early example of this practice in his account of Charles Sturt's 1844 expedition to the Lake Eyre region. Early in the expedition the party stayed at Moorundie on the River Murray where Edward Eyre, the Aboriginal Sub-Protector, arranged for a number of Aboriginal men to guide them north. About a month out of Moorundie, Sturt used Jacky, one of the guides, to carry a dispatch for the Governor back to Eyre at Moorundie. On 13 October Jacky, with two companions, reappeared in camp holding up the return message from the Governor and saying 'Jacky-flour and tomahawk'. He had travelled 300 miles in eleven days on the promise of flour and a tomahawk. Several days later he set off with another dispatch to carry with him on his return journey. 1

The employment of Aborigines as messengers was particularly characteristic of the marginal cattle country of central Australia where great distances often separated towns and stations, and where communications were difficult. From a European perspective, knowledge of the country and bush skills made Aborigines ideally suited to this task. Writing in 1902, Robert Bruce, owner of Coondambo Station in northern South Australia, indicated the frequency of the practice when he wrote that 'forty years ago blackfellows generally acted as postmen between stations' ${ }^{2}$ Despite what Bruce implies

1. Brock 1988, pp. 47-52.

2. Bruce 1973, pp. 173-175. 
in this passage, the practice continued to be a feature of outback life at least until the 1940s. Common sources of anecdotes on the subject are the expedition records of late colonial explorers and anthropologists, ${ }^{3}$ colonial reminiscences of bush life, ${ }^{4}$ and travel books, or books about outback life, published between the turn of the century and the Second World War. ${ }^{5}$

Over time the Aboriginal role of message carrier took on more formal, even ritual, qualities. According to most accounts, it became customary for the message to be carried in the end of a cleft stick. Alfred Howitt, in his discussion of messengers and message sticks, provides the most detailed account of the practice, and an explanation of its significance. In reference to the Kamilaroi of New South Wales, Howitt stated that they had 'official' heralds who could travel safely between adjoining tribes and that because they were well known they had no need to 'carry any badge or emblem of office'. However, if employed as a white man's messenger the paper was 'fastened in the end of a split stick':

Carrying this before him, he might pass safely through an enemy's country, because he was seen to be the white man's messenger, and if any harm were done to him, the tribe of the white man would be very angry. ${ }^{6}$

Howitt employed the technique in his own dealings with Aborigines. Returning to Adelaide from the Cooper's Creek region in the 1860s, presumably when engaged in the Burke and Wills rescue expedition, he reached a point where he had to send one of his guides back to his country:

To ensure his good treatment by any white man he might meet on his way through the settlements, I wrote a sort of passport which I folded up and put into the end of a stick. I explained to him what it was, and when he sorrowfully started on his long journey he carried the stick perpendicularly in his hand in front of himself, as a sort of talisman which would ensure safety.?

This is the earliest account I have found to the use of the 'split stick' to carry messages. Writing in the 1930s, R B Plowman's description of the technique of carrying paper yabber indicates that nothing much had changed in the seventy years since Howitt departed the Cooper:

As [the messenger] approached he held his right hand extended before him at the full length of his arm. Firmly grasped in his hand was a stick about twelve inches long and a quarter of an inch in diameter. The top end had been slit for about five inches, and in this slit was an envelope. The top of the slit was tied with a piece of string to keep it closed, and the envelope was thus held firmly in place. ${ }^{8}$

As Howitt explains, the stick in which the paper yabber was carried served as a visible symbol of neutrality to members of other tribal groups that the messenger might

3. Lindsay 1893, p. 46; Tietkens 1961, p. 16; Gillen 1968, p. 303.

4. Bruce 1973, pp. 173-75; Millett 1872, p. 81; Tilbrook, H. No Date, Reminiscences of Henry Hammond Tilbrook, 1889-1923, Mortlock Library PRG 180/1-4. bk. 1 series 1. vol. 1, pp. 19899.

5. Bolam 1927, p. 119; Brown \& Studdy-Clift 1990, p. 100; Plowman 1933, pp. 130-132; Spencer 1928, p. 546; Warburton 1937, p. 150.

6. Howitt 1904, p. 688.

7. Ibid.

8. Plowman 1933, pp. 129-130. 
encounter on his travels. Baldwin Spencer was of the same opinion when he wrote that the carrying of paper yabber in a cleft stick served as an 'emblem' which ensured the carrier's safety. He also noted the similarity to the traditional role of messengers:

The natives are quite accustomed to messengers travelling from tribe to tribe to summon distant groups to take part in sacred ceremonies. Such messengers always carried a token of some kind-very often a sacred stick or bullroarer. Their persons are always safe, and so this safety has been transferred to natives carrying 'paper yabbers' for the white man.

In most accounts of paper yabber it was made clear that it was customary to give the messenger a reward for his services, often flour and tobacco, perhaps an article of clothing, or simply a 'feed'. In 1932 the adventurer, Michael Terry, recorded in his diary that he gave an Aborigine 'a hunk of meat and bread and 1 stick of tobacco' as payment for carrying a paper yabber. ${ }^{10}$ Writing of his experiences on the west coast of South Australia in the 1880s the explorer Walter Tietkens made the point that Aborigines who carried these messages of ten had to travel large distances and pass through stations where they may not have been welcome, so he gave them a card to present at the stations along the way which read 'give him a feed and send him on'. ${ }^{11}$ He added that if it had not been for the card of introduction the messenger would have been 'hunted'.

A feature of many of the accounts of Aboriginal messengers is that they were of ten told to illustrate the good character of the subjects. In An Australian Parsonage; or, the Settler and the Savage in Western Australia, Mrs Edward Millet wrote that the Aborigines on her station willingly carried letters, the 'safe conveyance' of which they undertook with 'great fidelity': 'The value of such trustworthiness can be easily understood in a country thinly peopled, where the nearest post-office is often very far away' ${ }^{12}$

Tietkens wrote admiringly of the almost mystical endurance of the messengers who, perhaps having travelled hundreds of miles, would suddenly appear in camp and calmly announce 'paper yabber'. ${ }^{13}$ In the diary of his exploration of country inland from Fowler's Bay in 1879, Tietkens records an anecdote about his guide, 'Wantem', which not only illustrates the tremendous distances the messengers covered, but also the apparent equanimity with which they undertook their task:

Preparing a packet of letters for 'Wantem' to take to Fowler's Bay; it may appear incredible, but this fellow has just walked up to the Hills \& back, that is 160 miles. Tomorrow he starts for the Bay, 150 miles and the same distance back, total 460 miles, \& precious little he gets to eat; certainly no meat, \& he seems to take the order to go down to the Bay quite as a matter of course; he starts tomorrow with letters to England, Richmond, \& Levi, besides a few unimportant telegrams. ${ }^{14}$

\footnotetext{
9. Spencer 1928, p. 546 .

10. Terry, Michael, 29 August 1932, Diary of a prospecting expedition from Alice Springs to Laverton, 1932, South Australian Museum Anthropology Archives, A338.

11. Tietkens, W. H. No Date, Reminiscences of W. H. Tietkens, 1859-87, Mortlock Library PRG 1006/1, p. 93.

12. Millett 1872, p. 81 .

13. Tietkens, W. H. No Date, Reminiscences of W. H. Tietkens, 1859-87, Mortlock Library PRG 1006/1, p. 93.

14. Tietkins 1961, p. 16.
} 
In The Trans-Australian Wonderland, AG Bolam recorded another anecdote about Tietkens' use of Aboriginal messengers. Referring to his exploration of the Musgrave Ranges in the late 1870s, Bolam quotes Tietkens as saying:

A black used to carry my letters to Fowler's Bay. I put them in a forked stick, and said, 'Paper Yabber Yalata' (Yalata is the homestead station near Fowler's), and off he went without a word or a rag on his back, and brought my mail back, saying 'Paper yabber' - that was all the English he had. ${ }^{15}$

Of this great feat of endurance Tietkens admiringly observed 'No water on that one hundred miles, except Pidinga (a rock-hole about midway between Ooldea and Fowler's Bay). It was a wonderful service' ${ }^{16}$ The story was prefaced with the remark that it illustrated 'the reliability and loyalty on the part of the black'. ${ }^{17}$

The use of Aboriginal message carriers was usually a private matter but, as Brian Pope points out in a recent article, the Western Australian authorities made an attempt to institutionalise the practice. ${ }^{18}$ In 1848 two Aboriginal men were employed to carry mail, by foot, between Perth and Bunbury. The experiment was sufficiently successful for the government to officially encourage the practice and when the government tender for the carriage of mail was advertised in 1849 it included a passage stating that 'with a view of giving encouragement to the employment generally of Aborigines, the Government will sanction these Mails being carried by Natives under the guarantee of the contractor' ${ }^{19}$ Pope notes that a significant number of those employed were prisoners, given the inducement of working off part of their sentence if they undertook the job. The scheme lasted until about 1853 when, among other reasons, the increased volume of mail made its carriage by foot, and over long distances, unrealistic. ${ }^{20}$

David Lindsay, in his account of the Elder expedition of 1891, gives one instance of how the use of Aboriginal messengers at Esperance in Western Australia was unofficially institutionalised. Esperance had a Telegraph Station, and whenever a message was received a flag would be hoisted to notify people at the neighbouring sheep station, who would then dispatch a messenger for it. According to Lindsay, the 'flag was hoisted very often during my stay, and the black messengers kept going backwards and forwards pretty often'. 21

\section{The message}

Out of the tradition of Aboriginal letter carriers there developed a body of folklore about paper yabber. The earliest paper yabber story I am aware of, and the most commonly told version, comes from a South Australian newspaper, The Northern Argus. Writing from Strangways Springs on 2 June 1869, a 'northern correspondent' offered his readers the following anecdote:

15. Bolam 1927, p. 119.

16. Ibid.

17. Ibid.

18. Pope 1992.

19. Ibid., p. 68.

20. Ibid., pp. 76-77.

21. Lindsay 1893, p. 46. 
Some of the blackfellows cannot understand the notes that are frequently sent by them to out-stations. An incident occurred some time ago of a rather laughable nature. One of the natives was sent from the homestead to an out-station with some tobacco, and a note stating the quantity sent. Going on his way, the parcel got rather heavy, so he thought he would lighten it by taking two sticks; but how was he to manage this without the note seeing him he could not conceive. At last he thought of a plan, and took the tobacco, feeling satisfied that no person would be any the wiser for it, himself excepted. In due time he arrived at his destination; the hutkeeper consulted the note, examined the parcel, and found two sticks missing. He immediately proceeded to the native, who was not a great way off, and addressed him thus; 'This note tell me you stole two sticks baccy:' The blackfellow gave a jump in the air and was fairly nonplussed, and he confessed his guilt. His ingenious plan of procedure was this: He put the note under a very large stone, covering it all with sand, went some distance away, and took the tobacco. He said he thought the note could not see him. ${ }^{22}$

While humorous anecdotes about Aborigines became commonplace in newspaper columns and published reminiscences by the late colonial period, the paper yabber story became a favourite, being repeatedly told, in various forms, up to the present day. The editor of the South Australian Register was so taken by the Northern Argus story that he reprinted it verbatim in his newspaper the following day. ${ }^{23}$

A variation of the story, under the heading 'Paper Yabber' was published in The Young Men's Magazine in August 1874. It was prefaced with an explanation of how Aborigines were used to carry letters between stations. This account varies from the original by focussing less on the messenger than the medium-the mysterious and powerful properties of paper yabber. The yarn begins with a description of an isolated shepherd being harassed by Aborigines who were making constant demands for flour and sugar. The shepherd told them he had no supplies but while returning to his hut a stone was thrown and he was knocked unconscious and then beaten to death with waddies. After rifling the hut the shepherd's assailants found no supplies but

one of the murderers conceived the brilliant idea of resorting to 'Paper Yabber,' and after a good deal of palaver a leaf was torn out of the Bible which the poor murdered victim had just been reading. The blacks, not, of course, understanding the mysteries of writing, and thinking that any Paper Yabber was all potent and could carry out the sender's wishes, fully believed that the torn leaf, which they put in a cleft stick, would if carried to a station obtain for them flour and sugar in unheard of plenty.

They then set off for the head station where they presented their 'credentials' to the overseer. Understandably suspicious at being presented with a blood-stained page of a Bible, the overseer dispatched men to the hut where the murdered shepherd was discovered. 'The blacks', we are told, 'were hunted down and swift vengeance fell upon them':

From that time to this Paper Yabber has been looked upon as the white man's exclusive spirit, faithful to him and to him only, and the very name is sufficient to quiet the most troublesome Far North Native. The murderers believed, and told

22. The Northern Argus, 2 July 1869 , p. 3.

23. South Australian Register, 3 July 1869. 
their companions, that the Paper Yabber had betrayed them to the white man and there was no escape. ${ }^{24}$

According to the author, the incident demonstrated, to the 'simple minds' of the Aborigines, 'the dread power of Paper Yabber'. In this version, the story has become a parable; the superiority of the white man is manifested in paper yabber and any attempts to challenge it are surely and swiftly punished.

Perhaps the most elaborate account of the paper yabber story is that told by Robert Bruce in his reminiscences, published in $1902 .{ }^{25}$ The version of the story he told was essentially the one told originally in The Northern Argus, but considerably embroidered. He began by establishing the context, explaining how Aborigines acted as 'postmen between stations' and how the letter they carried was 'inserted in the end of the cleft stick'. Like the 1874 version, he played up the idea of the mysterious power of paper yabber. The Aborigines, he wrote, 'thought it contained a familiar spirit devoted to the service of the white man'.

In this version, the Aboriginal messenger, Toby, is given the task of taking a few pounds of tobacco to a neighbouring station, together with a letter that, unknown to him, certified the amount in the parcel. While Toby could not see the tobacco he could smell and feel it:

Poor Toby was dying for a smoke, so he persuaded himself that the paper spirit could not know the correct tally of plugs, and that, therefore, if he (Toby) prevented it seeing him open the parcel he would be safe. Yes, that was the idea, and so, with many apologies, the white man's familiar was hidden under a log, while Toby removed himself and parcel to a place hidden from the spirit's view, where he appropriated one stick of tobacco; then, figuratively speaking, he patted himself on the back for his cleverness, took the letter gingerly again by its sustaining wand and went home.

Toby arrived at his destination and handed over his cargo to Mr. M_ who immediately read the note, tallied up the number of plugs and, much to Toby's surprise, accused him of stealing one stick of tobacco:

'Him ruddy liar, that one paper yabba. Him no bin see 'em take him! What for him yabba like o' that!'

'All right! Him bin yabba you take 'em; Mr. A _ bin give 'em you like o' that,' said Mr. M_ holding up his hands and telegraphing the number of sticks with his finger, 'and you bin give me like o' that,' indicating one short. 'Now, trot out that stick or I'll thrash you!'

The latter argument was one too many for Toby, who produced his plunder with the remark, 'Looke here, Mitter M_ that one paper yabba, him no ruddy good! Him ruddy greedy wretch, him too much tell'em lie! Me only bin take 'em that one bacca, when him bin sit down long a log!'

Of course his naive apology was too much for Mr. M's gravity, so Toby not only escaped a thrashing but was permitted to keep the tobacco, with the warning, however, that he would get a dressing down with a stockwhip if he tried a like

24. The Young Men's Magazine, August 1874, vol. 2, no. 8, pp. 58-60.

25. Bruce 1973, pp. 173-175. 
experiment in future. It is needless to say that for some years subsequently a paper yabba was held in great respect.

Bruce's version of the story is essentially the same as the original 1869 version, but the elaborations are significant. The first of these is the 'context setting' introduction that was used in the 1874 variation-in both cases giving the story veracity by grounding it in the detail of lived experience. Perhaps the most interesting variation is the more complex denouement, characterised by the liberal use of Aboriginal pidgin. The author's familiarity with pidgin serves to underscore his authority on matters relating to the Aborigines, further strengthening the story's credibility. More importantly, Toby's seemingly 'simple-minded' language reinforces his 'simple-minded' appreciation of paper yabber. It is telling that when he is sent on the journey to the neighbouring station, Bruce refers to him not as Toby but as 'our simple friend'. The parable quality of the 1874 version is retained in this account, the final sentence assuring the reader that order had been restored with the Aborigines being reminded of white man's superiority. $^{26}$

The anthropologist Baldwin Spencer tells the same paper yabber story in his book Wanderings in Wild Australia, published in 1928 . He begins with an anecdote about his time at Powell's Creek in the Northern Territory and how, just as they were sitting down for their evening meal, two Aborigines appeared at camp carrying 'paper yabber' for one of their party. This gives him an opportunity for a scholarly digression on the significance of paper yabber-how the messages were carried in cleft sticks and how the use of such tokens ensured the messenger's safety as he or she travelled from tribe to tribe. Spencer then proceeded to tell his paper yabber story:

These 'paper yabbers' are a mystery to the unsophisticated native. On one occasion, a friend of ours sent a native with a small parcel of tobacco to a camp some distance away. At the same time he sent a message saying how many sticks the parcel contained. As a general rule a parcel such as this would be delivered intact, but the native knew what it contained and the temptation to open it and abstract a few sticks was too strong. When, on his arrival, he was taxed with the theft he was highly indignant with the 'paper yabber,' because he had hidden it away in the hollow of a log while he opened the parcel, so that it could not see what he was doing, and he thought that it had, in some unfair way, been watching him and had found out what he was doing and told the white man. 27

The form of the story is much the same as the earlier versions, although in this instance the paper yabber story is told without great elaboration, and takes second place to a discussion of its 'social' context, an approach that perhaps reflects the author's awareness of his scholarly reputation. Nonetheless, the message being conveyed is the same; the simple-mindedness of 'the unsophisticated native'. For Spencer the idea of Aboriginal inferiority was not just folk wisdom, it was scientific fact. On one occasion he contemptuously dismissed missionary efforts to 'elevate' the Aborigines because 'abstract ideas' were 'utterly beyond' their comprehension. ${ }^{28}$ Unlike the late

26. Tilbrook relates an abridged version of the same story. Tilbrook, H. No Date, Reminiscences of Henry Hammond Tilbrook, 1889-1923, Mortlock Library PRG 180/1-4. bk. 1 series 1. vol. 1, pp. 198-199.

27. Spencer 1928 , p. $546-547$.

28. Cited by Mulvaney \& Calaby 1985, p. 126. 
colonial versions which used Aboriginal pidgin to colour their telling, Spencer eschews it entirely. An explanation of this may lie in the fact that Spencer was an evolutionary anthropologist who romanticised 'pure and uncontaminated' Aboriginal people-the 'fossil culture' that was said to reveal the 'dawn of mankind'. He regarded those Aboriginal people who had 'lost' their culture as sad, if not contemptible, and he may have seen pidgin English as evidence of this loss, and somewhat demeaning to record.

In another variation of the story Aboriginal ignorance of paper yabber is exploited for punitive ends. In his book, The Red Centre, H Finlayson writes:

In the bad old days of early settlement undesirable bucks were got rid of by giving them 'paper yabbers' to deliver to distant neighbours. The note would read, 'Keep this b__ moving,' and he would be immediately sent on to the next man, and so on, until after a months travelling he would find himself stranded, perhaps in a hostile country, hundreds of miles from his own country. ${ }^{29}$

On the west coast of South Australia a well-known message carrier called 'Mailman Jimmy' is said to have been sent off to Eucla carrying a sledgehammer by a stationowner he had apparently offended..$^{30}$ Although the subject of the story differs, the message remains much the same; only a simple-minded person would fall for the 'keep the b_ moving' trick, or the 'sledgehammer' routine.

While cross-cultural communication provides ample opportunities for comic encounters, it is unlikely that the episodes described in the paper yabber folklore ever occurred. The very fact that the paper yabber episode concerning the 'tobacco thief' occurred so often and to so many different people lends perverse support to this view. This same story, adapted to local circumstances, appears to have been a universal tale on European frontiers. Consider, for instance, the following story from John Wilkins', Mercury; Or, the Secret and Swift Messenger, first published in London in 1641:

How strange a thing this Art of Writing did seem at its first Invention, we may guess by the late discovered Americans, who were amazed to see Men converse with Books, and could scarce make themselves to believe that a Paper could speak. . .

There is a pretty Relation to this Purpose, concerning an Indian Slave; who being sent by his Master with a Basket of Figs and a Letter, did by the Way eat up a great Part of his Carriage, conveying the Remainder unto the Person to whom he was directed; who when he had read the Letter, and not finding the Quantity of Figs answerable to what was spoken of, he accuses the Slave of eating them, telling him what the Letter said against him. But the Indian (notwithstanding this Proof) did confidently abjure the Fact, cursing the Paper, as being a false and lying Witness.

After this, being sent again with the like Carriage, and a Letter expressing the just Number of Figs, that were to be delivered, he did again, according to his former Practice, devour a great Part of the them by the Way; but before he meddled with any, (to prevent all following Accusations) he first took the Letter, and hid that under a great Stone, assuring himself, that if it did not see him eating the Figs, it could never tell of him; but being now more strongly accused than before, he con-

29. Finlayson 1935, pp. 74-75.

30. Tom Gara, personal communication, 18 December 1994. 
fesses the Fault, admiring the Divinity of the Paper, and for the future does promise his best Fidelity in every employment. ${ }^{31}$

Except for the fact that figs replace tobacco and that the Native American doubly incriminates himself, the story is identical, even down to the moral contained in the final line of the parable where the social order of white superiority and native inferiority is restored and reinforced. A similar story, set in eighteenth century California, is told by the anthropologist Edmund Carpenter in his book Oh, What a Blow that Phantom Gave Me! A missionary gave his native messenger some loaves of bread to carry to a colleague together with a note stating their number. The messenger ate part of his cargo and, because of the note, was discovered. On a second occasion he was given four loaves to carry, of which he ate two, but this time he took the precaution of hiding the accompanying note under a stone while he committed his crime, believing that if the note did not witness the act he could not be found out. ${ }^{32}$

A close variant of the story is recorded by M. Ilin in Black and White, The Story of Books, published in London in 1942. Although the author is strategically vague about time and place, the context is clearly the American south during the era of slavery. The subject of the story 'Sambo'-fresh off the boat from Africa-is given the task of carrying a basket of four roast chickens and 'a little piece of white paper' to his master. Along the way he eats one of the chickens, convinced that it won't be missed, only to be confounded when the 'paper' gives him away to his master. Given the task a second time he decides to be more careful so before 'he began to eat he hid the paper under a stone'. It made no difference, the 'cursed paper ... managed somehow to see everything and told the judge all about Sambo's little escapade! ${ }^{33}$

Not only have paper yabber stories been told in a variety of colonial settings, and for a very long period of time, but they are still being told. On South Australia's west coast the exploits of Koolbarri, popularly known as 'Mailman Jimmy', are well known. Mailman Jimmy began carrying messages and mail between Moopina station, near Eucla, and Fowlers Bay during the 1870 s, a round trip of 750 kilometres which he completed in three weeks on foot. According to the historian Tom Gara:

Mailman Jimmy is still remembered by many older residents of the west coast, both Aboriginal and European. I have been told by a number of Aboriginal and European people the story of the occasion when Mailman Jimmy smoked some of the tobacco he was supposed to deliver and was found out at the other end when the station-owner at Eucla read the note that Jimmy brought. On the next trip, Jimmy supposedly hid the note under a rock when he smoked the tobacco, but was still found out. ${ }^{34}$

\section{Conclusion}

The historical veracity of the story is, of course, irrelevant. The significance of the paper yabber story is that it served as a vehicle for a particular discursive category, that of the 'simple-minded blackfellow'. The humour of the story is built on a contrast between the

31. Cited in Eco 1992, pp. 40-41.

32. Carpenter 1976, p. 68.

33. Ilin 1942 , pp. $25-27$.

34. Tom Gara, personal communication, 18 December 1994. 
old and the new, the simple and the sophisticated; the Aborigine is portrayed as unable, perhaps incapable, of understanding the ways of the white man's world. This was a common theme in anecdotes about Aborigines that began to emerge in the last quarter of the nineteenth century. Similar stories were told about Aboriginal encounters with the electric telegraph, the phonograph and European clothing. It was also the basis of humour in newspaper cartoons. ${ }^{35}$ While presented as a distinctively Australian bush yarn, the North American versions of the story indicate that it had currency in a range of colonial settings for a very long period of time.

The story served as a sort of popular parable, rendering unproblematic the inferior status of the colonised subject. Indeed, some versions spell out the 'moral' by having the subject effectively 'acknowledge' his inferiority in the face of the 'awesome' and 'mysterious' power of the white man. To some extent the significance of the 'paper yabber' story lies in its very ordinariness: it is not set apart as a joke, as something amusing but unreal or untrue, rather, the teller always conveys the impression that the events were witnessed and that the story is authentic. The 'paper yabber' story provides a simple, but telling, insight into the way in which prejudice is 'naturalised' in popular culture.

Robert Foster is a lecturer in the History Department at the University of Adelaide

\section{References}

Bolam, G. 1927, The Trans-Australian Wonderland, Melbourne.

Brock, Daniel 1988, To the Desert with Sturt: A Diary of the 1844 Expedition, ed. Kenneth Peake-Jones, Adelaide.

Brown, R. \& Studdy-Clift, P. 1990, Bush Justice, Carlisle, Western Australia.

Bruce, Robert 1973, Reminiscences of an Old Squatter, facsimile of the 1902 edition, Adelaide.

Carpenter, Edmund, 1976, Oh, What a Blow That Phantom Gave Me! St. Albans, Hertfordshire.

Eco, Umberto 1992, Interpretation and overinterpretation, Cambridge.

Finlayson, H. H. 1935, The Red Centre, Man and Beast in the Heart of Australia, Sydney.

Foster, R. 1994, An Imaginary Dominion: The Representation and Treatment of Aborigines in South Australia 1834-1911, Ph.D thesis, University of Adelaide.

Gillen, F. J. 1968, Gillen's Diary. Camp Jottings of F. J. Gillen on the Spencer and Gillen Expedition across Australia, 1901-1902, Adelaide.

Howitt, A. W. 1904, Native Tribes of South-East Australia, London.

Ilin, M. 1942, Black on White, The Story of Books, London.

Lindsay, D 1893, 'Journal of the Elder Exploring Expedition, 1891', South Australian Parliamentary Papers, vol. 2, pt. 2, Adelaide.

Millett, E. (Mrs.) 1972, An Australian Parsonage; or, the Settler and the Savage in Western Australia, London.

35. Foster 1994, pp. 236-240. 
Mulvaney, D. J. \& Calaby, J. H. 1985, 'So Much That Is New': Baldwin Spencer, 1860-1929. A Biography, Melbourne.

Plowman, R. B. 1933, The Man from Oodnadatta, Sydney.

Pope, A. 1992, 'Aboriginal Message and Mail Carriers in South Western Australia in the Early and Mid-Nineteenth Century', in Portraits of the South West: Aborigines,

Women and the Environment, ed. B. K. de Garis, Perth, pp. 57-77.

South Australian Register.

Spencer, Baldwin 1928, Wanderings in Wild Australia, vol. II, London.

The Northern Argus.

The Young Men's Magazine.

Tietkens, W. H. 1961, Diary of the Exploration in South Australia of W. H. Tietkens Esq. F.R.G.S., 1879, Salisbury, South Australia.

Warburton, C. 1937, White Poppies, Sydney. 